\title{
Systemic Modelling for Relating Labour Market to Vocational Education
}

\author{
Evangelos C. Papakitsos* \\ Hellenic Ministry of Education, School of Pedagogical and Technological Education, \\ Department of Education, Isap-Irini, 141 21, Iraklio Attikis, Greece
}

Received: 22.02.2016; Accepted: 10.10.2016; Published: 19.12.2016

\begin{abstract}
The present study introduces a systemic model that demonstrates a description of the relationship between the labour-market and vocational education from the perspective of systemic theory. Based on the application of the relevant methodology, the two open social systems are identified and analyzed. Their key-features are presented and the points of contact are examined and linked, with the purpose to define more efficient manners of interrelation. This study has been conducted using information from the equivalent systems of Greece, as an example, and proposes this systemic method for further research in other countries as well.
\end{abstract}

Keywords: Labour-market, Systems inquiry, Vocational education, VET, Systemic modelling, Vocational Education and Training

\footnotetext{
${ }^{*}$ Corresponding author: papakitsev@sch.gr
}

ISSN: 2197-8646

http://www.ijrvet.net 


\section{Introduction}

Vocational education and training (VET) develops to its trainees expertise in all aspects of the trade. It prepares them for specific occupations at various levels in professional positions and careers such as engineering, nursing, accountancy, etc. The relevant learning is mainly based on manual or practical activities, including the apprenticeship type of training. VET is offered at the secondary, post-secondary, tertiary and further education levels. Since the labour-market increasingly requires higher levels of skill, as professional positions become more specialized, both governments and enterprises are more interested in the quality of continuous VET. Thus, the relationship between VET and the labour-market is obvious (Patiniotis, 2007a, 17; Nore and Lahn, 2014). This relationship is crucial but fragile because the developments in the economy precede the adaptation of educational systems (Patiniotis, 2007c, 383), thus the latter may fail follow as they respond slowly to economic developments (Patiniotis, 2007a, 19). Furthermore, there is a question of whether the enterprises are able to predict either their medium or their long-term needs in qualified personnel, so as to design VET according to a strategic planning.

Because of these conditions, prime international organizations are interested in studying ways to improve the connection between VET and labour-market. The Organization of Economic Cooperation and Development (OECD) has published a study of how to meet labour-market needs through the VET programmes (OECD, 2011). The World Economic Forum (WEF) is concerned about the skills mismatch in modern labour markets (WEF, 2014). Important conceptual tools for conducting the relevant research are the theories and models of interaction between VET and labour-market.

\section{Related Works}

The related theories are focused either on one of the constituent parts (VET or labourmarket) or on their links. The International Labour Office (ILO) has been concerned since 1999 with "the inability of public VET systems to respond quickly to new labour market requirements" and presents the Old vs. the New Paradigm of VET in industrialized and industrializing countries (ILO, 1999). Models like ORANI and MONASH attempt a labour-market forecasting in order to define skills training needs in Australia (Lilama, 2016; Richardson and Tan, 2007). An equivalent model of labour-market forecasting in the European Union is SBAS (Short-term Based Anticipatory System), developed by the European Centre for the Development of Vocational Training (CEDEFOP), that relies upon statistics and mathematical modelling (Kapetanios, 2015; Libeau, 2015; Marcellino, 2015; Pouliakas, 2015). Alternative models about the labour-market, besides Human Capital Theory, are also introduced in: the Segmentation Theory (Dickens and Lang, 1992), the Standard Competitive Model, the Efficiency Wage models, the models of Skill Mismatch, the model of Layard, Nickell and Jackman, the models of Matching Frictions (Brigden and Thomas, 2003) and the theory of Employment Systems (Marsden, 1999). 
Several models attempt to describe the links between education and work, notably the transition systems that refer to different approaches of studying the transitions of young people from education to employment (Wheelahan et al., 2012). The relevant literature associates the two main types of economies, namely the liberal market and the coordinated market economies, with models of skills formation, like the market model, the corporatist model, the developmental state and the neo-market models. Four explicit transition models are described by Grollman and Rauner (2007), namely:

- the model of Direct Transition,

- the model of Hardly Regulated Transition,

- the model of Regulated Overlapping Transition and

- the model of Shifted Transition.

All of them are associated with respective groups of countries. Other such cases are the Dual System, referring to the relationship of education and employment in Germany (Köhler, 2014), and the Education and Labour Market Outcomes (ELMO) model, which was developed to model the costs and benefits of education policies in Australia (Productivity Commission, 2013). Another conceptual approach in Australia uses the notion of skills ecosystems (Wheelahan et al., 2015).

Although the term system is frequently used in the previous approaches, none is compatible to the relevant framework (Betts, 1992) or to the General Systems Model (GSM, see: Sanders, 1991). While the feedback operation is often mentioned, it is not clear or defined what constitutes the input, the process, or the output of these systems. The herein hypothesis is that, without a systemic conceptual framework, important aspects of the complex social phenomena of education and employment may be neglected, thus potentially leading to insufficient conclusions and policy decisions. In this respect, Systems Inquiry is the framework that may provide useful concepts for the description of VET and the labour-market as systems, facilitating the study of their relationship.

\section{Systems Inquiry}

Systems Inquiry is composed of three related domains of study: Systems Theory, Systems Philosophy and Systems Methodology (Banathy, 1997; Banathy and Jenlink, 2001, 37). The goal of Systems Theory is to investigate the principles and the description models of the abstract organization of phenomena, as complex entities, independently of their nature or scale of existence in an interdisciplinary manner (Heylighen and Joslyn, 1992). A system, which is described as a complex set of components, their properties, relationships and processes, constitutes the main concept of this theory, conventionally originating from the work of Bertalanffy (Bertalanffy, 1968). The next domain is Systems Philosophy, concerning the issues of the systems view of the world and the application of systems thinking in dealing with both theoretical and real-world problems. The last 
domain, that of Systems Methodology, concerns the methods of generating knowledge about systems in general and the discovery of strategies, methods, models and tools for studying complex systems (Banathy and Jenlink, 2001, 40).

An important case of systems is the social ones (Banathy and Jenlink, 2001, 44). Their analysis, as a sociological paradigm, is influenced by the writings of Parsons (1977) and Luhmann (1995). They are adaptive systems that can change their behaviour through the process of feedback (Stichweh, 2011) and they resist quantitative modelling (Laszlo and Krippner, 1998). This particular class of systems includes the human learning processes, consequently education (Banathy and Jenlink, 2001, 47-49) and the labourmarket, as perceived herein. The relevant Systems Methodology offers a variety of conceptual tools, including cognitive maps (Laszlo et al., 1993), which may provide a conceptual representation of a particular social environment in the form of a model. Thus, since social phenomena can be also perceived as systems, they can be described through a model (Papakitsos and Katsigiannis, 2015, 25). Such a model, the Organizational Method for Analyzing Systems (OMAS), will be presented in the next section, before proceeding to relevant applications.

\section{Systemic Modelling}

The systemic model of OMAS (Papakitsos, 2010) is an evolution of similar earlier techniques of Software Engineering and Information Systems: the Structure Analysis and Design Technique (SADT) (Ross, 1977) and the Integration Definition for Function Modelling series of models (IDEF) (Grover and Kettinger, 2000). Both of them are not just compatible to the GSM but designed according to its concepts. The former is used as a standard model of developing Information Systems (Pressman 1987, 192-196), while the latter has been used for many years to conduct activities like engineering and reengineering, system control, data flow and other, in governmental agencies and private commercial and industrial enterprises.

According to ILO (1999), the world is in a transition process towards the so-called knowledge society, from the industrial to the information and communications era. The evolution of systemic techniques in this direction will be also beneficial and necessary for improving their applicability in all kinds of activities. This was the motivation behind the development of OMAS. The evolutionary process aimed at increasing the communicational aspects and abilities of the two previous models, in order to improve its understandability, thus being compatible to similar models of describing the process of human communication (Madoglou, 2007; Lasswell, 1991). OMAS-III is accompanied and depicted by a notational technique (Fig. 1), facilitating Systems Inquiry by forming cognitive maps. 


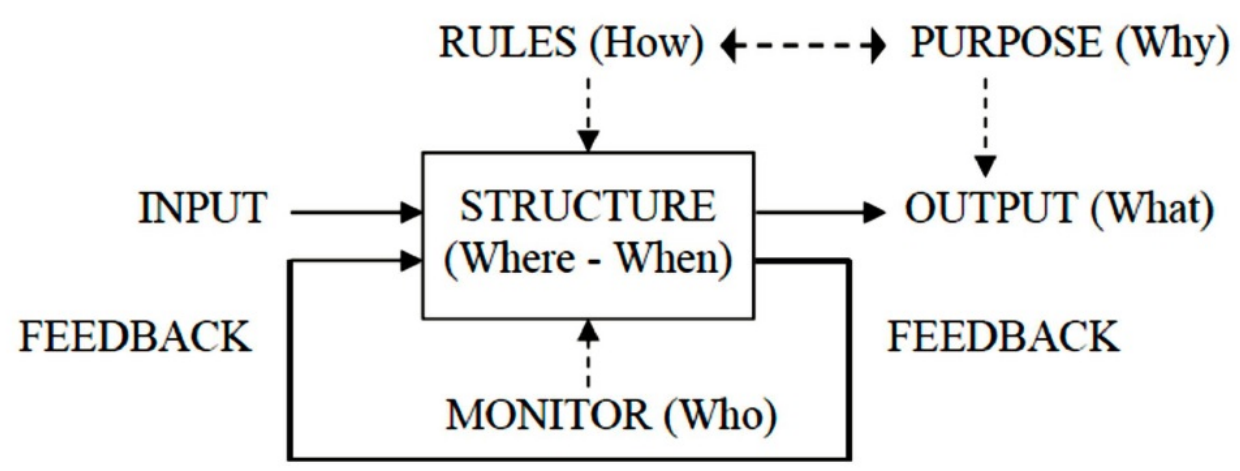

Figure 1: The Notational Technique of OMAS.

According to this systemic model (Papakitsos, 2013a,b), the functionality of each system is determined by five (5) factors:

- Input (Quantitative information): the data, the resources, the primary material and manpower entering the system.

- Output (What): the observed results of the systems functions, including the feedback operation.

- Purpose (Why): the reasons of existence and the necessity of studying the system.

- Rules (How): the legislation, regulations and natural or human-made conditions governing the operation of the system.

- Monitor (Who): people who interfere with the operation of the system in a regulatory and managerial manner.

- The Feedback is expressed as corrective activities for acquiring the desired Output and it can be applied not only to the Input but also to the rest of the factors, accordingly.

The relations between the above factors determine and/or affect the Structure, namely the operation of the parts that constitute the space-time aspects of the system (Where When). The core aspect of system's boundaries is defined according to whether the factors of the system are parts of it or not. For example, if the Rules of an educational institute, as a system, are solely internal regulations then this factor is part of this system, but if they are dictated by national legislation then the factor is not part of the system. OMAS-III has been used successfully in a variety of applications. Namely, it has been applied in: 
- the classical role of software development (Giachos, 2015; Papakitsos, 2011; Papakitsos, 2013b; Papakitsos, 2013c) and documentation standards (Papakitsos, 2014);

- project planning (Papakitsos, 2013a) and public administration (Papakitsos, 2015);

- curricula designing for vocational guidance projects (Papakitsos et al., 2015), language teaching (Makrygiannis and Papakitsos, 2015) and martial arts training (Papakitsos and Katsigiannis, 2015).

Therefore, the description of the vocational education system and the labour market system follows this particular model of perception, where Systems Theory can contribute constructively by using relevant modelling techniques (Papakitsos, 2008, 95-97).

In the systemic model of OMAS-III, we consider both the vocational education and the labour-market as two systems with their specific features. In order to determine any relationship between them we have to clarify firstly these specific features of each system. Then, we may identify the commonalities or points of contact and interaction, as well as the necessity of any relationship between them (Patiniotis, 2007a, 19). If such a necessity does exist, then we may examine whether it is covered adequately in the current situation by the relevant policies. Finally, if this coverage is not adequate, then the causes of failure have to be discovered and corrective actions should be proposed.

\section{Vocational Education and Training}

Maccia and Maccia (1966) and Banathy (1991) have been pioneers in applying systemic thinking in education, by defining the conceptual framework and the first models. Especially Banathy and Jenlink (2001) introduced the issue of systems thinking in VET. Herein, apart from OMAS-III, three models of systemic education will be briefly commented: SIGGS, A-GSBT and the bounded instability model.

SIGGS stands for Set, Information, Graph and General Systems theories (Maccia and Maccia, 1966; Maccia and Maccia, 1975; Maccia and Maccia, 1976). It was originally proposed as a systemic model of the school system; not of education in general. It was expanded later on by Frick (2004) to cover the entire education system. It is a model compatible to the GSM but it is highly complex at the initial level of analysis. It contains 201 hypotheses, not all of them verified, that minimize its understandability and usability. Yet, it can be converted to OMAS-III in a rather feasible manner.

The Axiomatic-General Systems Behavioral Theory (A-GSBT) consists of 14 theorems (Thompson, 2004), as they are applied to an educational context, 12 of which being theoretically validated. This model is used by Frick (Exter et al., 2004) for creating predicting software (SimEd) and for developing an Educational Systems Theory (Frick, 2004; Thomson, 2004). The predicting software will perform a simulation of the outcomes of an educational system according to the changes of values of the input factors. The advantage of OMAS-III in developing such simulating software is that OMAS-III is already based on standard software developing techniques, thus offering a unified conceptual environment. 
The bounded instability model (Delahaye, 2002) presents education as two parallel subsystems: the legitimate and the shadow system. Both subsystems are in a bounded instability, where the latter challenges the underlying values of the former, consequently facilitating change and adaptation without destruction. The model is focused on the processes and the feedback loops, while the input and output factors are not explicitly defined, according to GSM. Thus, its compatibility to GSM is not obvious, although feasible.

Finally, according to OMAS-III, VET can be described in a systemic manner as follows:

- Input $=$ expertise knowledge/skills; trainees/apprentices.

- Output = graduates, namely linking trainees to expertise knowledge/skills.

- Purpose = to provide skillful personnel (economic aspect); to minimize unemployment (social aspect).

- Rules = relevant policy; educational regulations and practices; teaching methodologies.

- Monitor = educators (all levels of education).

- Structure = levels of education (secondary, post-secondary, tertiary); duration of courses; topics of expertise and curricula.

- Feedback $=$ reports on the adequacy of the Output (e.g., success/failure rates; drop-out) and corrective proposals.

It should be noted that tertiary education is regarded as vocational, for any discipline (Patiniotis, 2007b, 174-177).

\section{Labour Market}

Regarding the models of labour-market, none of the previously mentioned (see: section 2. Related Works) explicitly considers the issue of systems thinking on this field. A notable exception is the autoregressive models in the context of System Dynamics (Álvarez et al., 2002). This is a family of simpler models with increasing importance within the field of economics and econometric analysis. By using a small number of parameters and variables, they can compete with the large macroeconomic models, in terms of their prediction capabilities. Their main feature is that the values of a variable (or a set of them) can be explained, based on the past values of this variable, at least partially. The members of this family exhibit an increasing complexity, from single variable models to vector autoregressive models (VAR) and structural vector autoregressive models (SVAR). The increased complexity regards the consideration of several variables and economy theory elements. They include diagrammatic notations that are not readily compatible to GSM, but a relevant conversion seems feasible. 
The labour-market system (henceforth LMS) can be also described in a systemic manner, as a field of activity of professionals, which can be analyzed using OMAS-III as follows:

- Input = employees/experts and their qualifications, including a complete personality profile.

- Output = employment (/unemployment); productivity.

- Purpose = national economic activity; personal and social needs.

- Rules = labour legislation; other rules, practices and features of the LMS.

- Monitor $=$ employers (private/public sector); labour-studying institutions.

- Structure = features, classification and distribution of occupations in a particular national economy.

- Feedback $=$ reports on the adequacy of the Output and corrective proposals.

Especially the qualifications of employees/experts (Input) can be classified as follows:

(i) Know-how: the theoretical and practical knowledge required for practicing a profession.

(ii) Professional skills: the ability to apply over time and effectively the expertise in the physical and social environment of a specific workplace (Koronaeou, 2007, 152-153). This ability is not obvious for the bearer of the corresponding knowhow (Koutroukis, 2012, 54-55; Melas, 2007, 406).

(iii) Certifications: the documents attesting the know-how and the skills of a professional. The expertise is certified through diplomas awarded by educational institutions and organizations. Wherever required, they are accompanied by permission to practice a profession (e.g., doctors, lawyers, engineers, etc.), as defined by the relevant national legislation (Rules). The skills are attested by certificates of experience and letters of recommendation provided by employers (Monitor).

For the limited scope of this presentation, the above analysis can be regarded as sufficient, considering that this article proposes merely a method of study, by providing an example of application, and not conclusive results of such an application through the gathering of specific data. Moreover, the acquisition of the required data exceeds national boundaries, as in the case of European Union, rising various issues and debates (e.g. Méhaut, 2006) that cannot be addressed herein. 


\section{Systemic Relationship}

In order to identify the links between the two systems (VET and LMS) we observe that formal qualifications (i) are mainly acquired at educational institutions and organizations (public or private). In addition, this knowledge can be usually certified by these very same institutions (iii). By the end of the apprenticeship, the graduate becomes a candidate employee/professional, having the relevant required qualifications (expertise and respective certification). Thus, a link between the two systems is that the Output of VET is the Input of LMS, through the relationship: professional (LMS Input) = graduate with certified expertise (VET Output).

Another obvious link is that the required by LMS (Input) professional knowledge is part of VET Input that will be formed in curricula. The Purposes of the two systems are also related, since they both refer to issues of economy and personal/social needs (Fig. 2). A less visible link is the one implemented through the practice of apprenticeship which directly relates the trainees (VET System) to working positions (LMS).

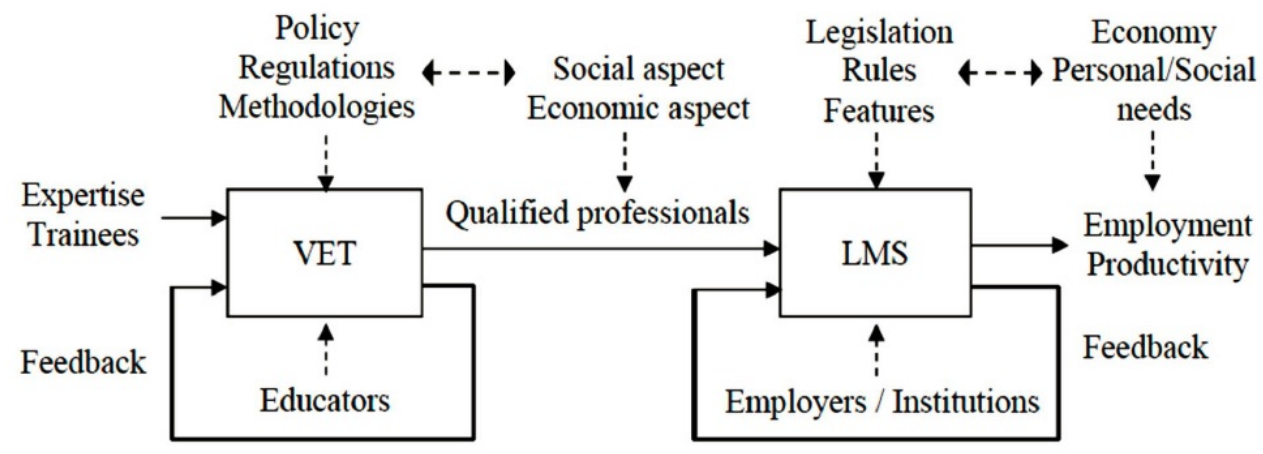

Figure 2: Systemic Relationship between Vocational Education and Labour Market.

If the previous relationship is socially and economically desirable then it is also necessary (Kalogiros et al., 2012, 187; Patiniotis, 2007a, 24; Valkanos et al., 2012, 33). This necessity is expressed through the educational policy, which sets out the operating conditions of VET (Rules). The analysis of a vocational educations national policy in relation to the factors of the system may reveal whether this necessity is adequately covered or not.

\section{Commentary}

If it is desirable to achieve a harmonious interconnection of VET to LMS, then the characteristics of the latter, as a recipient of the formers output, have to be well understood. For example, at the Output of LMS we can formulate criteria of efficiency as a part of the systems Feedback (Fig. 2), two of them regarding the professions (i) and the professionals (ii). 
According to Systems Inquiry, the aim is to ask and answer the proper questions (Banathy and Jenlink, 2001, 40):

(i) Are there ways of identifying trends in the labour market regarding the demand for a certain profession?

(ii) Do the professionals have the necessary training/skills?

Answering the first question, relevant information can be retrieved from various sources, depending on the established institutions in the country of study. Some suggestions include

- public agencies/services with respect to the number and type of enterprises that start or interrupt activity and the number of people involved;

- chambers and their studies (e.g. Papadosifaki, 2015, 49-51);

- institutions of tertiary/ongoing education, through their surveys;

- the daily and periodical press regarding labour demand/vacancies (Patiniotis, 2007b, 171), which requires a daily and systematic indexing (Kalogiros et al., 2012, 193).

The second question can be answered by the employers or, more specifically, by human resource managers. However, the well trained and skillful professionals are acquired by the VET institutions of various levels (secondary, tertiary or ongoing). Here, the problem of acquiring the suitable professionals is immediately visible: this particular part of Feedback is directed to LMS instead of the VET system (Fig. 2), which is the source of professionals and this kind of information is crucial for its efficient functioning (CEDEFOP, 2013a; CEDEFOP, 2013b). The Feedback of VET may include the designing of more efficient training methods/practices, which is also related to its efficient output (Fig. 2). Such a training practice that aims at a more efficient interconnection of VET to LMS is the apprenticeship. Thus, the perception of the two systems as separate ones is not adequate enough. A more effective solution would be to consider them as a set of subsystems, where a Feedback part of the second one (LMS) is directed to the Input of the first one (VET), concerning the common aspects, while there is also explicit feedback to each subsystem (Fig. 3). This approach is innovative, since the existing models describe either each system separately or the transition from one system to the other, yet without explicitly using the systemic conceptual framework. The systemic thinking in education (and VET in particular) is considered innovative (OECD, 2009). Nevertheless, although the designed processes arrive at the same conclusions (OECD, 2009, $26)$, this innovation is not disciplined and the overall plan is not conceptually systemic, according to the GSM. The conclusions stress the need of interconnecting the network of VET organizations to the labour market, through apprenticeship. The factors are implicitly referred to, making difficult to define an overall plan. 


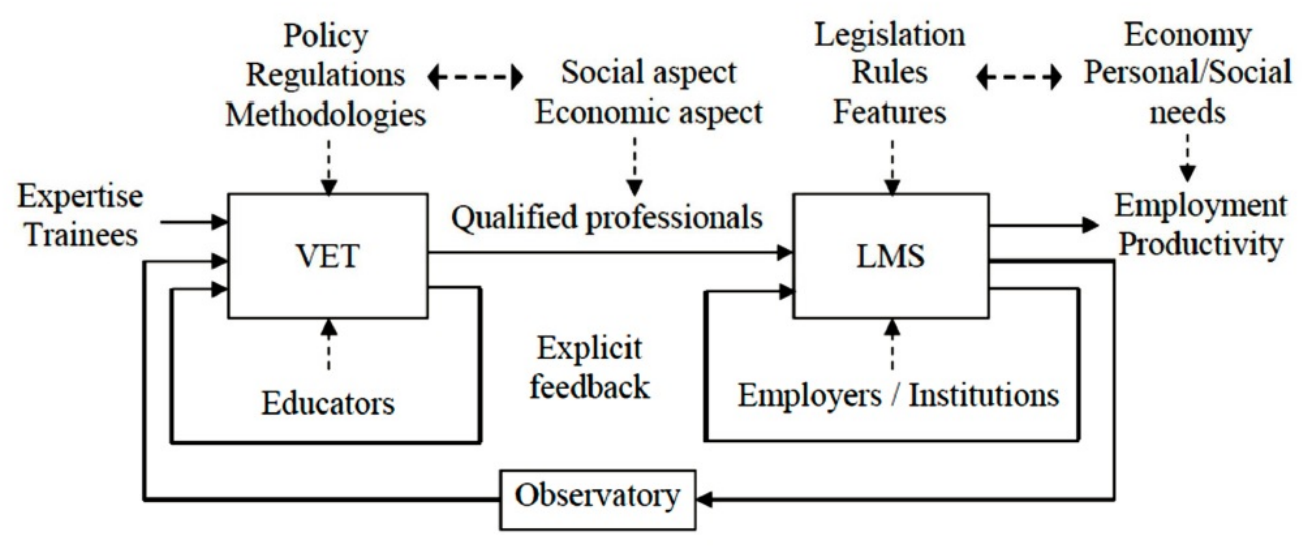

Figure 3: Common Feedback via an Observatory.

Because of the complexity involved, this mission requires the existence of an agency that will be set the above task of feedback-transfer from one subsystem to the other. At Fig. 3, this agency appears as an Observatory, being actually a third subsystem that may collect surveys of human resource adequacy. The results of the surveys can be accessible by the agencies of education for designing curricula more appropriate to the requirements of demanding job positions. The previous task is merely an example of the functions of an Observatory. Other suggestions may include:

- Its qualitative and quantitative contribution to the adequacy of the vocational guidance and career counseling services that facilitate the distribution of graduates and professionals to suitable job positions (Filippaki, 2007, 66-68; Watts, 2009; Kalogiros et al., 2012; Whiston and Blustein, 2013).

- The study of the ways that VET teachers can respond to their role of providing contemporary professional knowledge. For example, in the secondary VET of Greece, teachers have the legitimate right to work outside school in their expertise (e.g., engineering), after obtaining a relevant permission from their local educational authorities. So, an attempt is made to ensure the direct contact of them to the developments happening in their professional field and the transfer of these developments, as knowledge, to their students. Of course, the development of appropriate skills needs to be cultivated through continuous modernization of the content of the laboratory courses.

- To monitor the function of the more flexible institutions that offer ongoing VET at post-secondary level that can meet short-term training requirements (Patiniotis, 2007c, 378) and can be easily connected to apprenticeship/traineeship in workplaces.

Similar organizations exist in various forms in many countries or groups of them. Some notable examples are the National Centre for Vocational Education Research (NCVER) 
and Skills Australia (Lilama, 2016), both in Australia, and the European Centre for the Development of Vocational Training (CEDEFOP, 2013a; CEDEFOP, 2013b) of the European Commission. Because of the many stakeholders in VET (career services, business chambers, employers and employees associations, the Government, labour/VET research institutions), an Observatory could function as a linkage between them in the most suitable manner, depending on the country. The issues of linkage and of state diversity have attracted an international interest (Bertrand, 1998). However, the long-term effective training requires good scientific and technical knowledge backgrounds, as an asset acquired in formal general and vocational education (Patiniotis, 2007c, 383), as well as skills useful to professionals for their careers (self-confidence, creativity, collaboration ability, critical thinking, etc.).

Regarding the limitations of the present systemic modeling, via OMAS-III, these are the same ones as in any model of relevant studies. VET and labour-market are open social systems with many related factors. In subsequent levels of analysis, some of these factors can be underestimated or ignored, thus affecting the overall outcome of a study. The amount of data that is required from public or private agencies can be huge. For example, the Greek labour-market legislation consists of at least 107 Acts (Fotiou and Parastatidis, 2015), describing the rights of the various professionals of tertiary education degrees. Even recording such an amount of information can be a difficult task, not to mention discovering similarities, redundancies or contradictions. Moreover, introducing a coordinating organization, like an observatory, may add another cumbersome level of bureaucracy to the existing ones.

Nevertheless, expected limitations should not prevent further research in two main directions. The first one is the full application of OMAS-III in creating complete descriptions of the relation between VET and labour-market. The presented so-far description is merely a demonstration of concepts. The second direction of research concerns the usage of OMAS-III as a generic modelling technique. The comparison to other models should be further explored, aiming at the incorporation of their aspects, in any scale, into the present one for creating useful cognitive maps.

\section{Conclusions}

In the rapidly evolving economy, the labour market needs well-trained and skillful professionals that vocational education has to provide. The above relationship requires serious planning, accountability, methodical and systematic research (Patiniotis, 2007c, 385), cooperation and consensus between social groups, careful planning and coordination with the assistance of the State in the legislative field (Patiniotis, 2007a, 13). It has been demonstrated that Systems Methodology can offer useful tools/techniques/methods, like OMAS-III, for describing labour market and vocational education as social systems. This description aims at facilitating the comprehensive study of these complex social phenomena and supporting decision-making in the relevant educational and labour policies. 


\section{References}

Álvarez, De T.S.P., Crespo, M.A., Núñez, H.F., Usabiaga, I.C., \& Rebollo, S.Y. (2002). Autoregressive Models and System Dynamics: A Case Study for the Labor Market in Spain. In Proceedings of the $20^{\text {th }}$ System Dynamics Conference, System Dynamics Society. Palermo, Italy.

Banathy, B.H. (1991). Systems Design of Education: A Journey to Create the Future. Englewood Cliffs, N.J.: Educational Technology Publications Inc.

Banathy, B.H. (1997). The evolution of systems inquiry. Systems, 2(1), Techn. Univ. of Wroclaw, Poland.

Banathy, B.H., \& Jenlink, P.M. (2001). Systems Inquiry and its Application in Education. In D.H. Jonassen, \& J.C. Belland (Eds.), Handbook of Research for Educational Communications and Technology: I - Foundations for Research in Educational Communications and Technology. Bloomington; in: Association for Educational Communications and Technology.

Online: http://www.aect.org/edtech/ed1/.

Bertalanffy, von L. (1968). General system theory: Essays on its foundation and development. Rev. ed., New York: George Braziller.

Bertrand, O. (1998). Trends and Issues in Vocational Education and Training: A Perspective from Europe. IBERFOP, Seminario sobre Formación Profesional y Empleo: Encuentro Iberoamericano de Responsables de la Formación Profesional. Mexico D.F.; online: http://www.oei.org.co/iberfop/mexico4.htm.

Betts, F. (1992). How Systems Thinking Applies to Education. Improving School Quality, 50(3), 38-41.

Brigden, A., \& Thomas, J. (2003). What does economic theory tell us about labour market tightness? Working paper no. 185. London: Bank of England.

CEDEFOP (2013a). Renewing VET provision: Understanding feedback mechanisms between initial VET and the labour market. European Centre for the Development of Vocational Training, Research Paper No 37. Luxembourg: Publications Office of the European Union.

CEDEFOP (2013b). Labour market outcomes of vocational education in Europe: Evidence from the European Union labour force survey. European Centre for the Development of Vocational Training, Research Paper No 37. Luxembourg: Publications Office of the European Union.

Delahaye, B.L. (2002). The management of knowledge: A systems theory approach for vocational education and training. In J. Searle and D. Roebuck (Eds.), Proceedings of the $10^{\text {th }}$ Annual International Conference on Post-compulsory Education and Training, Surfers Paradise, Australia, 236-243.

Dickens, W.T., \& Lang, K. (1992). Labor Market Segmentation Theory: Reconsidering the Evidence. NBER Working Papers Series, Working Paper No. 4087. Cambridge, MA: National Bureau of Economic Research.

Exter, M.E., Hur, J.W., Koh, J., \& Wong, S.M. (2004). Educational Systems Theory Study. Indiana University, Bloomington; online:

https://www.indiana.edu/ tedfrick/est/verification14theorems.pdf. 
Filippaki, N. (2007). School Vocational Guidance. Modern perspectives. In Papamichael, G. and Kapoli, C. (Eds.). Counselling Horizons for School

Guidance-SOS Orientation, Athens: Panteion University of Social and Political Sciences, 46-81.

Fotiou, N., \& Parastatidis, K. (2015). Professional Rights. Vocational Guidance Gate. Online: http://www.mysep.gr.

Frick, T.W. (2004). Educational Systems Theory. Indiana University, Bloomington. Online: https://www.indiana.edu/ tedfrick/siggs.html.

Giachos, I. (2015). Implementation of OMAS-III as a Grammar Formalism for Robotic Applications. Postgraduate Dissertation (MSc). National \& Kapodistrian University of Athens and National Technical University of Athens.

Grollman, P., \& Rauner, F. (Eds) (2007). International Perspectives on Teachers and Lecturers in Technical and Vocational Education. Dordrecht: Springer.

Grover, V., \& Kettinger, W.J. (2000). Process Think: Winning Perspectives for Business Change in the Information Age, IGI Global. DOI: 10.4018/978-1-878289-68-1.

Heylighen, F., \& Joslyn, C. (1992). Systems Theory. In Heylighen, F., Joslyn, C., \& Turchin, V. (Eds.). Principia Cybernetica Web (Brussels: Principia Cybernetica); online: http://pespmc1.vub.ac.be/systheor.html.

ILO. (1999). The Changing Role of Government and Other Stakeholders in Vocational Education and Training. International Labour Office, Employment and Training Department, Training Policies and Systems Branch. Second International Congress on Technical and Vocational Education, Seoul, Republic of Korea, 26-30.

Kalogiros, B., Taousanis, C., \& Kotios, K. (2012). The career choices of young people in the period of economic crisis and the mapping of the labour market in 2011-2012. In the Proceedings of the Panhellenic Conference: "Counselling and Vocational Guidance in Education and Employment: Redefinition of the Content of the Institution in Contemporary Economic, Social and Scientific Developments", Piraeus: ELESYP, 187-196.

Kapetanios, G. (2015). SBAS a Sectoral Based Anticipatory System for the European Labour Market: Task A2.2: Refinements of the Econometric Technology of the SBAS Project. EU-SBAS information day, Brussels, 13 February 2015. European Centre for the Development of Vocational Training (CEDEFOP); online: http://www.cedefop.europa.eu/en/themes/identifying-skills-needs.

Köhler, T. (2014). Patterns of Inter-Institutional and Inter-Organizational Collaboration Strengthening the Relationship between VET and Labour Market for Developing a Professional Work Force. In the Proceedings of the International Conference on Vocational Education and Training (ICVET) 2014. Online: http://eprints.uny.ac.i d/id/eprint/24369

Koronaeou, A. (2007). Curricular and Extracurricular Education. Career skills in the new era. In Papamichael, G., \& Kapoli, C. (Eds.), Counselling Horizons for School Guidance-SOS Orientation, Athens: Panteion University of Social and Political Sciences, 149-162.

Koutroukis, T. (2012). Professional searches at the era of recession: old wine in new bottles. In the Proceedings of the Panhellenic Conference: "Counselling and Vo- 
cational Guidance in Education and Employment: Redefinition of the Content of the Institution in Contemporary Economic, Social and Scientific Developments", Piraeus: ELESYP, 52-58.

Lasswell, D. H. (1991). The structure and function of communication in society. In Livieratos, K., \& Fragkoulis, T. (Eds.). The message of medium. The explosion of massive communication; Athens: Alexandria, 65-83.

Laszlo, A., \& Krippner, S. (1998). Systems Theories: Their Origins, Foundations, and Development. In J.S. Jordan (Ed.), Systems Theories and A Priori Aspects of Perception. Amsterdam: Elsevier Science, 47-74.

Laszlo, E., \& Masulli, I. (1993) with Artigiani, R., \& Csányi, V. (Eds.). The evolution of cognitive maps: New paradigms for the twenty-first century. New York: Gordon and Breach.

Libeau, F. (2015). A Short-term Based Anticipatory System for the European Labour Market Trends, Skills Developments and VET Policy: The EU-SBAS Tool. EUSBAS information day, Brussels, 13 February 2015. European Centre for the Development of Vocational Training (CEDEFOP). Online:

http://www.cedefop.europa.eu/en/themes/identifying-skills-needs

Lilama (2016). Labour Market Forecasting to Meet Skills Training Needs: Australia, General Policy. Linguistic Policy for the Labour Market network. Retrieved from http://www.lilama.org/uploads/documents/Labour\%20Market \%20Forecasting\%20-\%20Australia.pdf.

Luhmann, N. (1995). Social Systems. Stanford, Cal.: Stanford U.P.

Maccia, E.S., \& Maccia, G.S. (1966). Development of educational theory derived from three theory models. Project N. 5-0638. Washington, D.C.: U.S. Office of Education.

Maccia, E.S., \& Maccia, G.S. (1976). The logic of the SIGGS theory model. San Francisco, CA: American Educational Research Association.

Maccia, G.S., Maccia, E.S. (1975). SIGGS theory as a systems theory for education which enhances the quality of life. In Systems thinking and the quality of life: Proceedings of the 1975 Annual Meeting; The Society for General Systems Research, 228-233.

Madoglou, A. (2007). Models, basic principles and skills of communication. In Papamichael, G., \& Kapoli, C. (Eds.). Counselling Horizons for School Guidance-SOS Orientation Athens; Panteion University of Social and Political Sciences, 508-530.

Makrygiannis, P.S., \& Papakitsos, E.C. (2015). Writing or programming an essay? An interdisciplinary systemic experiment in language teaching. Journal of Global Research in Education and Social Science, 4(1), 16-24.

Marcellino, M. (2015). SBAS a Sectoral Based Anticipatory System for the European Labour Market: An Overview of the Methodology. EU-SBAS information day, Brussels, 13 February 2015. European Centre for the Development of Vocational Training (CEDEFOP). Online: http://www.cedefop.europa.eu/en/ themes/identifying-skills-needs.

Marsden, D. (1999). A Theory of Employment Systems: Micro-Foundations of Societal Diversity. Oxford University Press. 
Méhaut, P. (2006). Key concepts and debates in the French VET system and labour market. Paper for the seminar "Developing a European Qualification

Framework- Conceptual and Labour Market Questions". London: King's College, June 2006. Online: http://www.nuffieldfoundation.org/sites/default/ files/FranceQuickScanNov071.pdf.

Melas, K. (2007). Unemployment, Employment Policies, Vocational Training and Industrial Relations. In Papamichael, G., \& Kapoli, C. (Eds.). Counselling Horizons for School Guidance-SOS Orientation; Athens: Panteion University of Social and Political Sciences, 391-440.

Nore, H., \& Lahn, L.C. (2014). International Journal for Research in Vocational Education and Training. Bridging the Gap between Work and Education in Vocational Education and Training. A study of Norwegian Apprenticeship Training Offices and E-portfolio Systems. 1(1), 21-34. DOI: 10.13152/IJRVET.1.1.2.

OECD (2009). Systemic Innovation in the Australian VET System: Country Case Study Report. OECD/CERI Study of Systemic Innovation in Vocational Education and Training; online: http://www.oecd.org/australia/42243354.pdf.

OECD (2011). OECD reviews of vocational education and training: Learning for Jobs. Organization of Economic Cooperation and Development, Directorate for Education, Education and Training Policy Division, May 2011. Online: www.oecd.org/edu/lear ningforjobs

Papadosifaki, E. (2015). The failure of the transformation of the growth model of the economy. Development, 9/2015, 49-51.

Papakitsos, E.C. (2008). Seminar Subjects of Vocational Guidance in Education; Athens: M.C.C. Christodoulatou.

Papakitsos, E. (2010). Organizational Method of Analysing Systems. Athens: E.K. Thessalou.

Papakitsos, E.C. (2011). Basic meanings of Linguistic Computing. National \& Kapodistrian University of Athens and National Technical University of Athens.

Papakitsos, E. (2013a). The Systemic Modelling via Military Practice at the Service of any Operational Planning. International Journal of Academic Research in Business and Social Science, 3(9), 176-190.

Papakitsos, E.C. (2013b). Linguistic Software Engineering: I. Preparation. Athens: National Library of Greece.

Papakitsos, E. (2013c). Mini Translator: Software of bidirectional machine translation between the artificial languages of Toki Pona and Minimal Extent Free Greek. Athens: National Library of Greece.

Papakitsos, E.C. (2014). An application of Cognitive Ergonomics to the Quality Assurance of Software Documentation. International Journal of Academic Research in Computer Sciences and Electrical Engineering, 1(1), 16-30.

Papakitsos, E.C. (2015). A Systemic Application of Graph Theory in Issues of Public Administration. International Journal of Management Sciences, 5(11), 716-722.

Papakitsos, E.C., \& Katsigiannis, S.V. (2015). An Application of Systems Theory to the Perception of Combat in Martial Arts. International Journal of Martial Arts, Volume 1, 25-34. 
Papakitsos, E.C., Makrygiannis, P.S., \& Tseles, D.I. (2015). Modelling the application of Blended-Learning in Career Guidance projects of the Hellenic Secondary Education. International Scientific Conference eRA-10: The SynEnergy Forum. Piraeus University of Applied Sciences, Greece, 23-25.

Parsons, T. (1977). Social Systems and the Evolution of Action Theory. New York: Free Press.

Patiniotis, N. (2007a). Current approaches to relations of Education, Employment, School Vocational Guidance. In Papamichael, G., \& Kapoli, C. (Eds.). Counselling Horizons for School Guidance-SOS Orientation; Athens: Panteion University of Social and Political Sciences, 8-42.

Patiniotis, N. (2007b). Social adaptation processes during the integration into the labour market. In: Papamichael, G., \& Kapoli, C. (Eds.). Counselling Horizons for School Guidance-SOS Orientation. Athens: Panteion University of Social and Political Sciences, 164-187.

Patiniotis, N. (2007c). Education and Labour Market in Greece; in: Papamichael, G., \& Kapoli, C. (Eds.). Counselling Horizons for School Guidance-SOS Orientation. Athens: Panteion University of Social and Political Sciences, 374-389.

Pouliakas, K. (2015). Forecasting the Present: A Short-term Sector-Based Anticipatory System. EU-SBAS information day, Brussels, 13 February 2015. European Centre for the Development of Vocational Training (CEDEFOP); online: http://www.cedef op.europa.eu/en/themes/identifying-skills-needs

Productivity Commission (2013). The Education and Labour Market Outcomes Model: Documentation and User Guide. Technical Note. Canberra: Australian Government.

Pressman, R. (1987). Software Engineering: A Practitioner's Approach. $2^{\text {nd }}$ Edition. London: McGraw-Hill.

Richardson, S., \& Tan, Y. (2007). Forecasting future demands: What we can and cannot know. Adelaide: NCVER.

Ross, D.T. (1977). Structured Analysis: A Language for Communicating Ideas. IEEE Trans. Software Engineering, January 1977, 16-34.

Sanders, M. (1991). Communication technology : today and tomorrow. Glencoe, Macmillan/McGraw-Hill, Lake Forrest, III

Stichweh, R. (2011). Systems Theory. In B. Badie et al. (Eds.), International Encyclopedia of Political Science. New York: Sage.

Thompson, K. (2004). A-GSBT: Axiomatic-general systems behavioral theory; online: http://www.raven58technologies.com/index.html.

Valkanos, E., Mardas, G., \& Mardas, N. (2012). The contribution of vocational guidance and vocational education and training to employment. In the Proceedings of the Panhellenic Conference: "Counselling and Vocational Guidance in Education and Employment: Redefinition of the Content of the Institution in Contemporary Economic, Social and Scientific Developments"; Piraeus: ELESYP, 33-51.

Watts, A.G. (2009). The Relationship of Career Guidance to VET. Paris: OECD; online: http://www.oecd.org/education/innovation-education/44246616.pdf. 
WEF (2014). Matching Skills and Labour Market Needs: Building Social Partnerships for Better Skills and Better Jobs. Global Agenda Council on Employment, REF 060114, Davos-Klosters, Switzerland, January 2014. Geneva: World Economic Forum.

Wheelahan, L., Buchanan, J., \& Yu, S. (2015). Linking qualifications and the labour market through capabilities and vocational streams, Adelaide: NCVER.

Wheelahan, L., Moodie, G., \& Buchanan, J. (2012). Using the 'transition systems' literature to understand the position of VET in Australia (paper-04); online: http://avetra.org.au/wp-content/uploads/2012/05/2012_Wheelahan_paper_04. docx.

Whiston, S.C, \& Blustein, D.L. (2013). The impact of career interventions: Preparing our citizens for the 21st century jobs. (Research Report). National Career Development Association and the Society for Vocational Psychology. 


\section{Acknowledgements}

The author would like to thank Mr. Agathoklis Vasileiadis, BA and MA in English Literature, for the proofreading of this article and Mrs. S. Kataki for typing the text.

\section{Bibliographical notes}

Dr Evangelos Papakitsos is a professor of Informatics, Physics, Linguistic Computing and Vocational Guidance at the Hellenic Ministry of Education, Research and Religious Affairs, serving as a regional supervisor of Vocational Guidance in secondary and postsecondary education, general and vocational. He is also an adjunct professor at the Department of Education at the School of Pedagogical and Technological Education, Greece. His research interests focus on various topics of his academic expertise. 